\title{
LETTERS
}

\section{Further developments in the literature on RAAS inhibitors and COVID-19}

An international cohort study of 8910 patients ${ }^{1}$ that found no association between use of renin-angiotensinaldosterone system (RAAS) inhibitors and risk of in-hospital death has been retracted over concerns of the validity of its data sources. ${ }^{2}$ We had included this article in our update of the evolving evidence on the risk of potential harm associated with use of RAAS inhibitors in patients with coronavirus disease 2019 (COVID-19), ${ }^{3}$ but not in our original CMAJ article. ${ }^{4}$

Therefore, we reviewed the sources of data from all studies cited in our articles. To the best of our knowledge, no other concerns exist.

As a further update, a recently published matched case-population study of more than 1100 adults admitted to hospital with COVID-19 found no association between use of RAAS inhibitors and risk of admission to hospital, intensive care unit or death. ${ }^{5}$

Given the evidence to date, we continue to support our original conclusion and the recommendations from multiple professional societies that "patients prescribed RAAS inhibitors should remain on them during the COVID-19 pandemic, pending release of high-quality and replicable data to the contrary." 3,4

\section{Kieran L. Quinn MD MSc}

General internist and palliative care physician, Department of Medicine, University of Toronto; Division of General Internal Medicine and Geriatrics, Sinai Health System; Institute of Health Policy, Management and Evaluation, University of Toronto, Toronto, Ont.

\section{Michael Fralick MD PhD}

Clinician scientist, Department of Medicine, University of Toronto; Division of General Internal Medicine and Geriatrics, Sinai Health System, Toronto, Ont.

\section{Jonathan S. Zipursky MD}

Resident in internal medicine, Department of Medicine, University of Toronto; Institute of Health Policy, Management and Evaluation, University of Toronto; Division of Clinical Pharmacology and Toxicology, Sunnybrook Health Sciences Centre, Toronto, Ont.

\section{Nathan M. Stall MD}

PhD student, Department of Medicine, University of Toronto; Division of General Internal Medicine and Geriatrics, Sinai Health System; Institute of Health Policy, Management and Evaluation, University of Toronto, Toronto, Ont.

Cite as: CMAJ 2020 June 29;192:E727. doi: $10.1503 / \mathrm{cmaj} .76076$

\section{References}

1. Mehra MR, Desai SS, Kuy S, et al. Cardiovascular disease, drug therapy, and mortality in COVID-19. N Engl J Med 2020 May 1;NEJMoa2007621 [Epub ahead of print]. doi: 10.1056/NEJMoa2007621.

2. Mehra MR, Desai SS, Kuy S, et al. Retraction: Cardiovascular disease, drug therapy, and mortality in COVID-19. N Engl J Med 2020 June 4;NEJMc2021225 [Epub ahead of print]. doi: 10.1056/NEJMc2021225.

3. Quinn KL, Fralick M, Zipursky JS, et al. Good things come in threes (and sometimes fours) [letter]. CMAJ 2020;192:E611.

4. Quinn KL, Fralick M, Zipursky JS, et al. Reninangiotensin-aldosterone system inhibitors and COVID-19. CMAJ 2020;192:E553-4.

5. de Abajo FJ, Rodríguez-Martín S, Lerma V, et al. Use of renin-angiotensin-aldosterone system inhibitors and risk of COVID-19 requiring admission to hospital: a case-population study. Lancet 2020;395:1705-14.

Competing interests: None declared. 